\title{
Drip versus surface irrigation in long term environmental modelling of soil-water-plant exposed to saline water
}

\author{
L. P. Kasmaei \& P. E. Jansson \\ Department of Land and Water Recourses Engineering, \\ The Royal Institute of Technology, Sweden
}

\begin{abstract}
A physically based soil-water storage model with two surface and drip irrigation scenarios in response to saline water was used in the semi-arid Gordonia district in South Africa. The model (CoupModel) consists of several different modules that couples mass and energy flow models with dynamic biotic models of plant and its environment. The simulation period accounted for non-productive water losses, salt accumulation in root zone, and salt transport to below aquifer via deep percolation. The monitoring of biomass production with respect to water consumption and soil osmotic pressure indicted a decline in crop yield due to the water and salt stresses.

The drip scenario had a better functionality in terms of the water wastage as the soil evaporation decreased by $40 \%$. However, the productive water consumption decreased by $20 \%$ due to insufficient leaching fraction while salt accumulation increased drastically in the entire root zone. We found that salt could be flushed out from the root zone by more leaching but the water wastage increases as well as increasing the possibility of salinization beneath aquifer.

The soil-water and plant ecosystem responds differently to salinity in different water management practices. Salt as a source of pollution can either stabilizes the soil by accumulation in the root zone causing anthropogenic soil desertification or can percolate it to beneath the aquifer resulting to long-term salinization. The findings of our study could sever to improve different management schemes in similar semi-arid regions.

Keywords: soil-water-plant modelling, coupmodel, drip and surface irrigation, soil evaporation, transpiration, chloride balance, water balance.
\end{abstract}




\section{Introduction}

Increasing soil and water salinity is the most significant environmental problems facing nearly $7 \%$ of the earth's total land surface, which sometimes causes irreversible losses of both aquatic and terrestrial ecosystems [1].

Applying saline water without sustainable management strategies in arid and semi-arid climate condition, where evapotranspiration is much more than precipitation may cause anthropogenic catastrophe of secondary inland desertification due to underestimated leaching fraction [2]. Or aquifer salinization may occur due to long-term over-estimated leaching where soluble salt leaches beneath aquifer and deteriorates groundwater quality [3].

Reduction in crop yield caused by osmotic stress and physiological drought condition [4], soil dispersion reasoned by higher exchangeable sodium and decrease in soil infiltration rate $[4,5]$, are the most important anthropogenic inland salinization side effects.

One of the objectives was to assemble an overall sketch of ecosystem behaviour as a soil-water storage model in long term run based on physical approach in form of multi-process numerical ecosystem modelling equipped with two water management scenarios of drip and surface irrigation. Environmental modelling as virtual model to simulate real processes in nature by using digital data-driven computational tools is economically affordable in such analyses [6].

The main objectives were to find drip irrigation functionality versus surface in optimizing water consumption in water scarce areas while keeping prior goals of equal food productivity and ecosystem sustainability in long term.

\section{Material}

The site is located in semi-arid region with coordinates of $-28^{\circ} 27^{\prime} 0^{\prime \prime}$ South, $21^{\circ}$ $15^{\prime} 0^{\prime \prime}$ East and altitude $545 \mathrm{~m}$ from previous studies of Karlberg [7] and Durand [8] in Gordonia district, Northern Cape province of South Africa.

Important meteorological driving forces were air temperature, net radiation, air humidity, duration of bright sunshine and wind speed collected from 1st January 1975 to 31 st December of the year 2004 at nearby weather station Keimoes in form of measured time series data. Previous study by Durand [8], showed precipitation and temperature were considered to be the most important drivers influencing crop production in South Africa, especially in Gordonia as the driest district with the lowest rainfall.

Soil hydraulic data sampled at Hatfield experimental farm, Pretoria [9] used to represent soil properties. Soil sample contains of $60 \%$ sand, $10 \%$ silt and $30 \%$ clay with bulk density of $1120 \mathrm{~kg} / \mathrm{m}^{-3}$, PH (H2O) of $4.73,1.11 \%$ of carbon storage, residual water of $1 \%$ and finally initial salt concentration (TDS) of $10 \mathrm{mg} / \mathrm{l}$. By applying the percentage of three constituents of the soil in USDA triangular diagram, soil texture of the experimental field classified as Sandy Clay Loam soil type.

Irrigated water extracted from a trans-boundary aquifer located at Karoo shared by South Africa, Namibia and Botswana. The volume of water in the 
aquifer is large in amount but poor in quality and varies from brackish to saline water [10] so that only suitable for stock watering and irrigating of particular plants. Water from Karoo aquifer contains considerable amount of soluble salt (3195 mg/l) at the beginning of simulation and according to FAO standards categorized as Moderately Saline water.

Tomato crop chosen as predominant agricultural product, sown $1^{\text {st }}$ October, emerged ten days later after $10^{\text {th }}$ October, set fruits after two and half months around $15^{\text {th }}$ December and finally harvested after 163 days on $23^{\text {rd }}$ March.

\section{Method and model description}

To build a multi process conceptual model, different sub-models added to soil module with different degree of coupling one by one to achieve. A Lumped method used and one point of the experimental area represent the whole district with generalized results for the whole system.

Important system parameters, driving variables and boundary conditions having direct or reverse impact on energy and mass transport taken into account in Richards equation for water flows and corresponding Fourier equation for heat flows in soil media [11].

Water storage through soil media derived from Richards equation [12] optimized and reformulated by adding precipitation and irrigation as sources of inflow/input and runoff, evapotranspiration, drainage as output/outflows removed from the system plus leaching as internal output from root zone to the below layers joining later to deep percolation.

CoupModel tool as multi process-oriented computational tool used here to manifest the most fundamental abiotic and biotic ecosystem related processes, in different compartments of layered soil profile, vegetation, and atmosphere.

The core of the CoupModel is a one-dimensional physical base representation of a soil profile for simulating thermal and hydrological processes, and also biological processes regulating carbon and nitrogen turnover and chloride tracing in Soil-Plant-Atmosphere environment [11].

\subsection{Soil-water storage model}

Soil profile considered homogeneous with 2.1 meter depth in 11 layers, $10 \mathrm{~cm}$ thickness for the first layer and $20 \mathrm{~cm}$ for the rest of 10 layers. Soil surface was the upper boundary where salt and water enters by irrigation and precipitation. The lower boundary was bottom layer of the soil profile in depth of 2.1 meter.

To demonstrate hydrological processes in unsaturated zone, basic soil hydraulic characteristics such as soil porosity and water content calculated based on soil texture and partly pedofunction database. Soil water content $(\theta)$ expressed as a percentage and converted into a depth of water over volume depth of soil in water budget calculation at four conditions of saturation point $\theta \mathrm{s}$, matric point after drainage by gravity $\theta_{\text {mat }}$, field capacity $\theta_{\mathrm{fc}}$ and wilting point $\theta_{\mathrm{w}}$ from Saxton and Rawls [13] for moisture held at $0,-10,-33,-1500 \mathrm{kPa}$ pressure respectively. Two main outputs in soil-water storage system were soil water retention curve 
(PF) at selected tensions based on Brooks and Corey functions [14] and unsaturated hydraulic conductivity at selected tensions based on Mualem function [15].

\subsection{Water management model}

Irrigation introduced as sort of automatic input for soil-water budget taking place at certain soil moisture condition in root zone before water stress causes irreversible damages to plant. Amount of applied water and irrigation intervals were based on maintaining favourable water content in root zone to avoid plant water stress. Also, more water for leaching soluble salt through the root zone considered to prevent salinity stress. Thus irrigation regulated by controlling the actual soil water storage in number of soil layers in which root system extracts plant water demand.

This critical threshold of plant water stress assumed $50 \%$ of available water in the root zone equal to water content at field capacity minus wilting point; fc-WP [16]. Minimum soil water storage in the first forth layers of soil, when soil water content depletes to the fraction of available water in the root zone (FA) at which water stress begins. Irrigation occasions scheduled daily with $100 \%$ efficiency, and all irrigated water in both surface and drip application, added to the soil directly not above the plan till soil water content raised to field capacity point.

\subsubsection{Surface and drip irrigation}

Surface irrigation inflow applied at the rate of $210 \mathrm{~mm} /$ day. Maximum surface irrigation runtime without runoff was 4 hours equal to elapsed time to reach basic infiltration rate of Sandy Clay Loam soil type. Basic infiltration rate of the soil was considered $500 \mathrm{~mm} /$ day from USNRCS raw infiltration data for 5 types of soils family [17].

In point source emitters, average drip irrigation precipitation rate scheduled to be $500 \mathrm{~mm} /$ day equal to soil basic infiltration rate moving vertically through vadose zone. Maximum runtime without runoff calculated 1.4 hours so that water could penetrate in soil layers without exceeding soil infiltration rate at elapsed time.

Distribution coefficient for different soil layers in the effective root zone depth calculated geometrically as a portion of soil wetted volume held in each specified layer to the total 3-D cone-shaped water infiltration pattern for each emitter.

Fraction Wetted area of each dripper considered 0.35 in this model for sandyloamy clay soil with light texture [18].

\subsection{Leaching requirement model}

Leaching requirement model (LR) with lowest value of leaching fraction (LF) added to pass through root zone and keep salt concentration at desirable level preventing yield reduction for a steady-state salt balance.

Salt concentration at desired level for plant salinity tolerance could be represented by crop yield decline in the root zone. Thus tomato salt tolerance to 
produce economic yields with dissolved salt in soil solution, osmotic pressure at different yield reduction [5] and finally physiological drought condition [4] taken into account in calculating leaching fraction. A general function yield response to allowable salt concentration in root zone without crop yield reduction for tomato plant expressed as electrical conductivity $\mathrm{EC}_{\mathrm{e}}$ at minimum threshold salinity with full yield potential equal to $\mathrm{EC}_{\mathrm{emin}}$ of $2.5 \mathrm{ds} / \mathrm{m}$ with slope reduction $\mathrm{Y}_{\mathrm{d}}$ of $9.9 \% / \mathrm{ds} \mathrm{m}^{-1}$ reaching zero level threshold at $\mathrm{EC}_{\text {emax }}$ of $12.5 \mathrm{ds} / \mathrm{m}$ where minimum osmotic pressure threshold tolerable for the plant was $-8000 \mathrm{~cm}$.

Leachate $\mathrm{EC}\left(\mathrm{EC}_{\text {leaching }}\right)$ of $7.5 \mathrm{ds} / \mathrm{m}$ and leaching requirement (LR) of $66 \%$ of gross irrigation were required for conventional surface irrigation with periodic leaching from Rhoades [19] empirical formula (fig. 1).

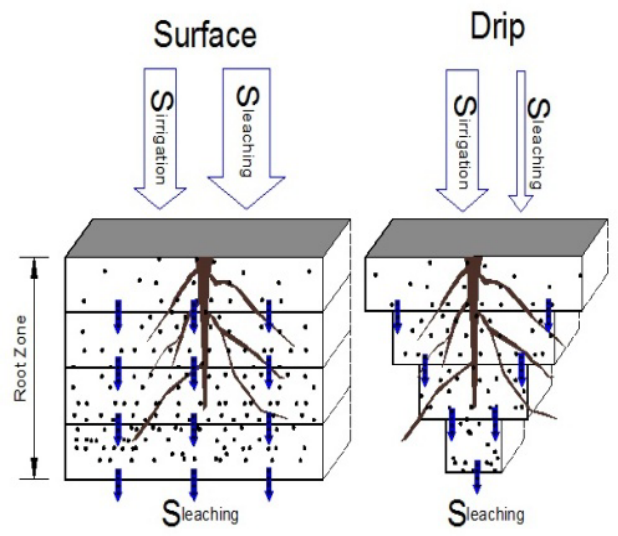

Figure 1: Leaching pattern in root zone for surface and drip irrigation.

In drip irrigation with high-irrigation frequency, leaching requirement was lower than conventional irrigation due to continuous uniform water application aiding plant to tolerate higher range of salinity [20]. Thus $\mathrm{EC}_{\text {leaching }}$ and (LR) for sub-surface drip irrigation were estimated $25 \mathrm{ds} / \mathrm{m}, 19 \%$ respectively (fig. 1).

\subsection{Plant assimilation pattern and soil nutrient model}

Most important plant's growing pattern and characteristics defined to the system by introducing crop coefficient at different growth stage, maximum yield, leaf index, and root depth and its distributions and canopy size as a guide for simulating dynamic plant physiology in growing period. Also plant's respiration, photosynthesis, and nutrients and water uptake and finally its interaction with abiotic environment assembled in different modules in CoupModel tool.

No external input of fertilizer, manure introduced to the soil and simulation started with carbon initial humus of $5000 \mathrm{~g}$ and organic and mineral nitrogen of $510 \mathrm{~g}$ and $9.1 \mathrm{~g}$ respectively assuming homogeneously distribution in all layers of soil with no litter remedies above or below the ground. 


\subsection{Soil evaporation and plant transpiration model}

Evaporation from soil surface calculated based on an iterative solution of surface energy balance including both water and heat fluxes obeying law of conservation of energy. Net radiation portion $\left(\mathrm{R}_{\mathrm{s}}\right)$ received at soil surface assumed to be equal to sum of latent heat flux $\left(\mathrm{L}_{\mathrm{v}} \mathrm{E}_{\mathrm{s}}\right)$, sensible heat flux $\left(\mathrm{H}_{\mathrm{s}}\right)$ and heat flux to soil $\left(\mathrm{q}_{\mathrm{h}}\right)$ summarized by Male and Granger [21] and iterative calculations continued until fluxes reach a balance.

Transpiration was set equal to water uptake by root of an explicit big leaf plant and pressure head response approach to calculate plant water uptake from soil layers considering plant as a fraction of atmospheric demand of water. In multiplicative response function, actual transpiration was based on potential transpiration in response to soil pressure head, osmotic potential, and soil temperature and root distribution in plant root zone [22]. Potential transpiration calculated from Penman's combination equation determined only by meteorological factors in the form given by Monteith [23].

\subsection{Chloride balance model}

Salt balance model used as a quantified summary of all inputs and outputs of soluble salt for a defined volume or depth of soil during simulation time with no generation or decomposition of salt inside considering only convection salt transport. Salt accumulation occurred whenever salt input exceeds outputs.

Salt input sources were from irrigated water and atmospheric depositions. Wet chloride deposition recorded in Karoo weather station as rainwater hydrochemical inputs in this region following seasonal rainfall pattern. Dry chloride fallout reported to be approximately $30 \%$ of the total atmospheric deposition [24].

\section{Result}

\subsection{Water balance}

The amount of irrigated water applied in the drip scenario was $48 \%$ less than surface scenario showing the goal of less water consumption successfully performed in the drip irrigation.

Soil evaporation as non-productive loss was the highest fraction of total evapotranspiration in both scenarios; for surface irrigation $70 \%$ and slightly lower with $62 \%$ for drip irrigation. Although, a considerable portion of evaporated water $(>35 \%)$ occurred in non-cultivating season when precipitation and stored soil water were the only source of water in both scenarios.

Transpiration as productive water consumption obtained $17 \%$ and $23 \%$ of total water applied in surface and drip scenarios respectively.

After each heavily intense rainfall in both scenarios, transpiration rose significantly in next growing season due to mass removal of salt from root zone, especially in topmost layer of soil causing better condition for water uptake; more noticeable in drip scenario though. 
The ratio between actual and potential transpiration (ETa/ETp) was used to indicate the impact of water shortage on transpiration with equal value at initial growth stage in both scenarios. ETa/ETp ratio increased steadily for the entire growing season in surface irrigation, whereas in drip scenario decreased sharply to 0.26 in mid-season and then surged up to 0.41 at the last growth stage. Taking into account both scenarios equally exposed to other stress factors of temperature, degree of radiation saturation. ETa/ETp ratio indicated plant irrigated with drip system was more stressed by insufficient water application and salinity, particularly in mid-season (fig. 2, 3).

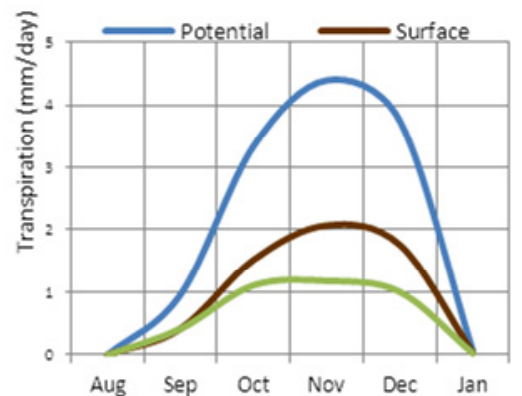

Figure 2: Potential and Actual transpiration.

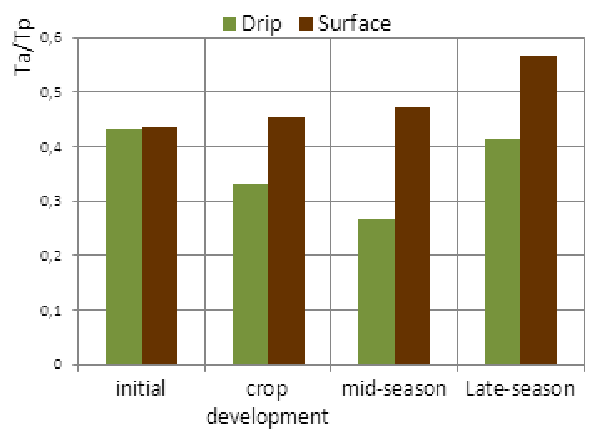

Figure 3: $\quad$ ETa/ETp in different growth stages.

Runoffs via deep percolation reoccurred regularly within irrigation occasions in surface scenario for the entire simulation period and influenced by rainfall intensity in high extent.

Thus whenever the amount of precipitation reaches above $40 \mathrm{~mm} /$ day during or after irrigation period, a pick flow appeared in total runoff mostly leaves the system via deep percolation. In drip scenario, no regular runoff appeared during irrigation occurrences; instead water left the system via percolation every time the amount of precipitation was more than $25 \mathrm{~mm} /$ day mostly occurred in nongrowing season (fig. 4, 5).

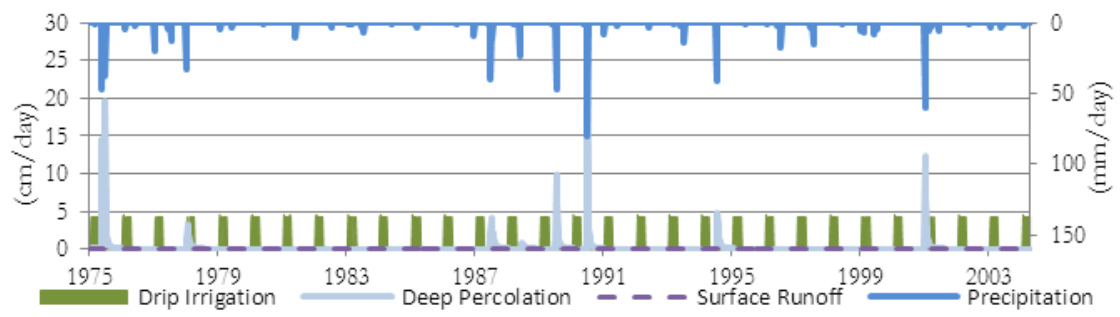

Figure 4: $\quad$ System runoffs trends in surface irrigation. 


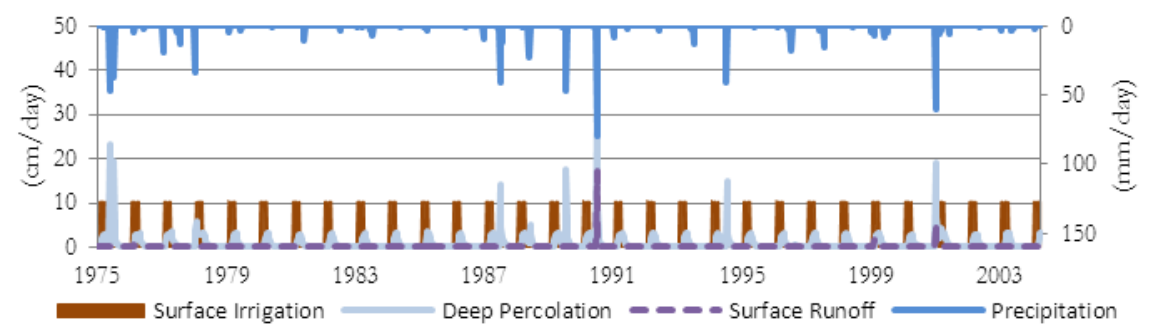

Figure 5: $\quad$ System runoffs in drip irrigation.

Soil water budget in surface scenario was around field capacity above $20 \%$ for the entire growing season except December while in drip scenario soil water content in all four layers was mostly below field capacity.

\subsection{Salinity in root zone}

Due to soil intolerable osmotic pressure for cultivated plant, possibility of physiological drought was much higher in drip scenario and plant's root only enable to extract water from depth of 10-30 $\mathrm{cm}$. In surface scenario, osmotic pressure was above minimum threshold except top $10 \mathrm{~cm}$ soil layer in which water mostly evaporated than extracted by plant's root (fig. 6).
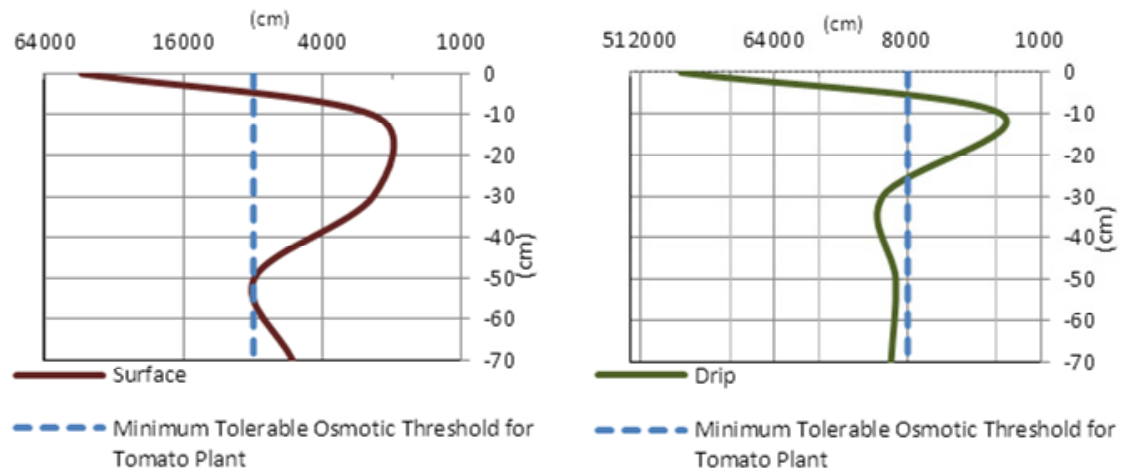

Figure 6: Mean logarithmic values of osmotic pressure in root zone at the end of simulation.

In case of irrigation by drip system, salt distribution in the first $10 \mathrm{~cm}$ of soil was highly governed by precipitation intensity so that high removals occurred whenever precipitation exceeds above $25 \mathrm{~mm}$ /day causing runoff in the system and indicating why transpiration raises after each heavily intense rainfall.

In the surface scenario salt removals from soil top layer carried uniform distributions following leaching trend, though there were flushes after intense rainfalls (fig 7). 

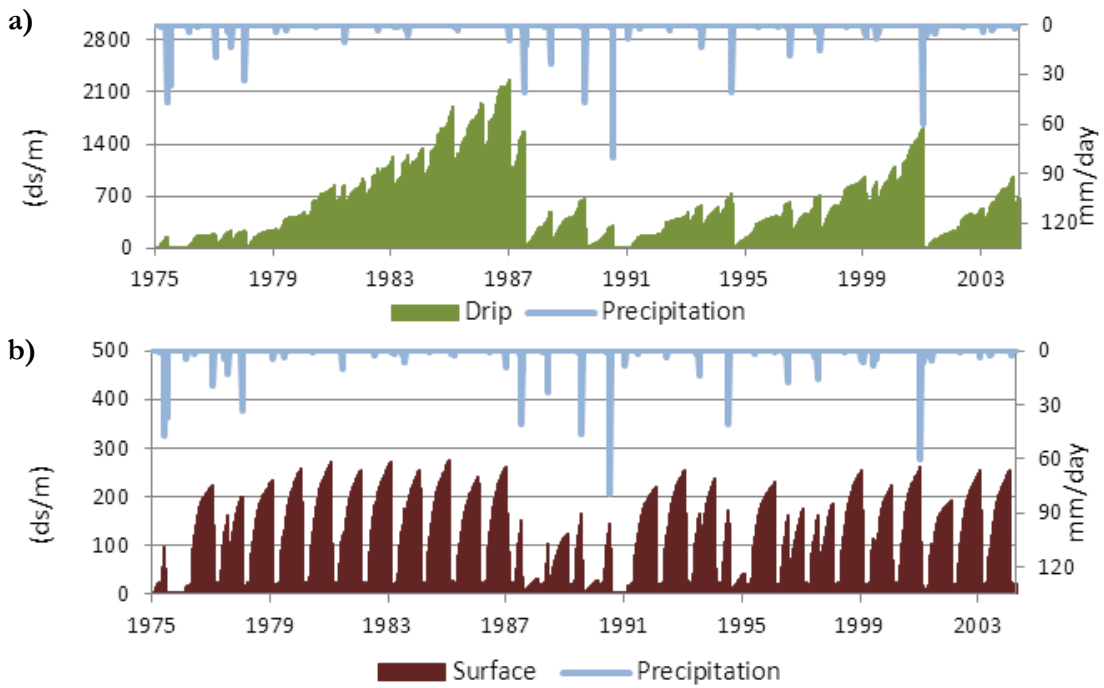

Figure 7: Salt concentration in top $10 \mathrm{~cm}$ and precipitation; a) drip and b) surface.

Salt leached out of root zone with mean values of 7.3 and $3.0 \mathrm{mg} / \mathrm{m} 2 /$ day in surface and drip scenario respectively showing salt leached out via deep percolation two times more in the surface comparing to drip scenario.

In the drip scenario, salt concentration has been increased progressively after each irrigation occasion in first soil layer and then flushed out drastically due to high intense rainfall to beneath soil layers. This trend repeated for the entire simulation period completely under influence of precipitation events. In the surface scenario, salt concentration in first layer was mostly influenced by irrigation and leaching than precipitation.

\subsection{Carbon and nitrogen balance}

Soil carbon stored below the ground in the surface scenario was two times higher than drip indicating root growth and its distribution was deteriorated in soil irrigated by drip application. Carbon storage above the ground in the surface scenario was $30 \%$ more than drip, indicating plant growth above the ground had better performance in the surface scenario too but not as significant as root growth.

Total respiration from cultivated plant and soil were about $85 \%$ and $88 \%$ of plant photosynthesis for drip and surface scenario respectively showing carbon uptake from atmosphere via photosynthesis was slightly more than carbon release via respiration in both scenarios.

The ratio between accumulated photosynthesis and transpiration represented as water use efficiency (WUE) was used for evaluating ecosystem efficiency.

Although WUE had better performance at the first decade in the drip scenario, but for the second and third decades of simulation, WUE was performing slightly 
better in the surface scenario. Despite of applying twice water in the surface application, WUE increased just insignificantly which could be contemplated that plant was also stressed by other factors of climate like high temperature and degree of radiation saturation than water management in this model (fig. 8).

a)

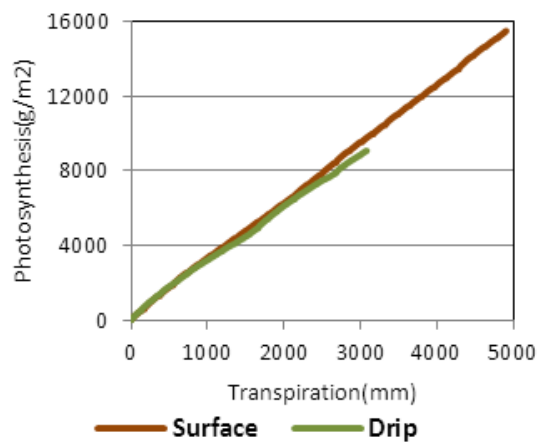

b)

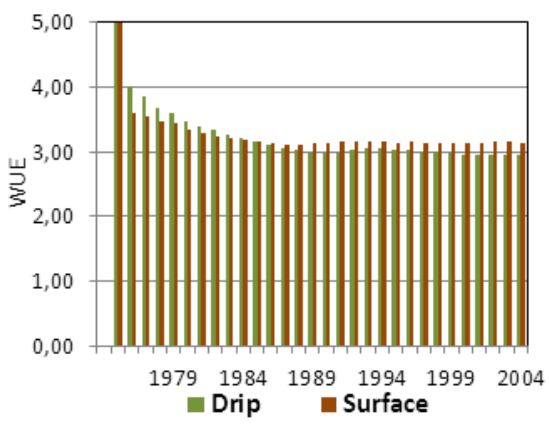

Figure 8: a) Accumulated biomass as a function of accumulated transpiration and b) Mean yearly water use efficiency trend.

Also soil nitrogen budget as another indicator for soil productivity with defined initial condition showed organic storage of nitrogen increased with $15 \%$ for surface and $10 \%$ for the drip scenario stating richer soil in humus and litter in both cases at the end of simulation period. This phenomenon expected since tomato fruit as small part of the plant harvested and the rest of root, stem and leaves have been joining the system biomass budget.

\section{Discussion}

Comparison of water balance results in scenarios proved better functionality to perform less water consumption by drip system; almost $50 \%$ less than surface by decreasing soil evaporation. However productive water consumption for drip irrigation decreased $20 \%$.

An assessment of salt concentration in root zone indicated that leaching fraction in the drip scenario was insufficient and needed to be justified in higher values. Salt could be washed out from root zone by more leaching in drip scenario, but adding more water results more water consumption and more possibility of aquifer salinization in long term.

There was a constant salt removal trend in surface application during simulation period via deep percolation; almost 2.5 times more than drip scenario. And this may raise the risk of salinization and groundwater quality deterioration in case of shallow water table. Whereas in drip scenario simulation, salt mostly remained in soil layers; 1.6 times more than surface indicating higher risk of desertification, especially in root zone. 
Table 1: $\quad$ Mean yearly accumulated values of water balance state.

\begin{tabular}{|l|c|c|}
\hline \multirow{2}{*}{ Water Balance Components } & \multicolumn{2}{|c|}{ Irrigation System } \\
\cline { 2 - 3 } & Drip & Surface \\
\hline Irrigation(I) & 460 & 876 \\
Precipitation(P) & 216 & 216 \\
Soil Evaporation(E) & 354 & 581 \\
Transpiration(T) & 153 & 186 \\
Evaporation from Intercepted Water(EI) & 1.5 & 1.5 \\
Surface Runoff(S) & 0 & 7 \\
Deep Percolation(DP) & 79 & 332 \\
\hline Total Input (P+ I) & 676 & 1092 \\
Total Output (E+T+EI+S+DP) & 682 & 1091 \\
\hline
\end{tabular}

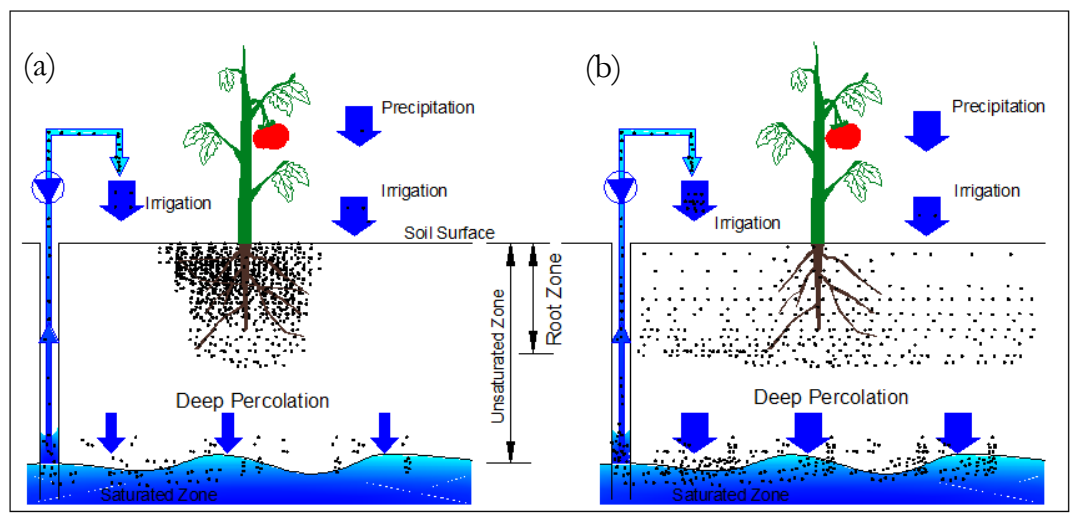

Figure 9: Salt fate after long term simulation model irrigated with saline water; a) drip and b) surface.

Total carbon budget above and below the ground showed almost $25 \%$ lower soil productivity for the system irrigated by drip. Result from nitrogen budget indicated steady built up in organic nitrogen in both cases resulting richer soil in humus and litter; $15 \%$ for surface and $10 \%$ for drip at the end of simulation.

\section{Conclusions}

The goal of setting drip system versus surface irrigation into water-soil-plant model was to demonstrate an optimum sustainable design using multi-criteria on efficiency for both production levels and environmental impacts.

The simulation results showed that sustainable water allocations to food production and ecosystem without serious damages to soil and water body achieved neither in conventional surface irrigation nor in subsurface drip when water with $3196 \mathrm{mg} / \mathrm{l}$ salt concentration considered as source of water in Gordonia region. 
Saline water irrigation has introduced as a potential resource in water scarce areas aiming more crop production and more cultivated land to eradicate extreme poverty and hunger. However, it may give unintentional irreversible results of gradual secondary desertification or water quality deterioration in aquifers.

The modelling approach showed how our prior goals may be achieved without serious damages to environment in long term.

Results from simulations proved a secure sustainable irrigation method is a necessity to obtain a proper balance of accumulated salt in root zone and leachate into groundwater when saline water is the only source in arid and semi-arid areas. Further studies may include soil remedies applications like mulching to reduce direct evaporation from soil, manure to keep balance of nutrient in soil, drainage to increase seepage.

\section{References}

[1] Szabolcs, I., Soils and Salinization. Handbook of Plant and Crop Stress. Edited by Pessarakali, M. and Dekker, M., New York, 311 p, 1994.

[2] Duncan, R.R., Carrow, R.N., and Huck, M.T., Irrigating with Saline Water Sources (Chapter 6). Turf-Grass and Landscape Irrigation Water Quality. CRC Press, 347 p., 2008.

[3] Blinn, D. W. and Bailey, P.C.E, Land-use Influence on Stream Water Quality and Diatom Communities in Victoria Australia: A Response to Secondary Salinization. Journal of HydroBiologia. 466, pp. 231-244, 2001.

[4] Hiscock, K., Hydrogeology-Principles and Practice (Chapter 6). Blackwell, 389 p, 2005.

[5] USDA, Leaching Requirements for Salinity Control (Chapter 2). Irrigation Water Requirements, National Engineering Handbook, pp. 98-110, 1993.

[6] Lundmark, A., Monitoring Transport and Fate of De-icing Salt in the Roadside Environment - Modelling and Field Measurements. Royal Institute of Technology, Sweden, TRITA-LWR PhD 1038, 24 p, 2008.

[7] Karlberg, L., Irrigation with Saline Water Using Low-Cost Drip Irrigation System in Sub-Saharan Africa. Royal Institute of Technology, Sweden, TRITA-LWR. PhD 1020, 36 p, 2005.

[8] Durand, W., Assessing the Impact of Climate Change on Crop Water Use in South Africa. University of Pretoria, South Africa Arc-Grain Crops Institute, Potchefstroom, Private Bag X1251, South Africa, CEEPA Discussion Paper. No. 28, 60 p, 2006.

[9] Tesfamariam, E., Modelling the Soil Water Balance of Canola (Hyola 60). M.Sc. Agric. Dissert, University of Pretoria, South Africa, 107 p, 2004.

[10] ISARM, Shared Aquifer Resources Managing in Africa. International Shared Aquifer Resource Management. UNESCO, 216 p, 2004.

[11] Jansson, P.E., and Moon, D.S., A Coupled Model of Water, Heat and Mass Transfer Using Object- Orientation to Improve Flexibility and Functionality. Journal of Environmental Modelling and Software. 16, pp. 37-46, 2001. 
[12] Richards, L.A., Capillary Conduction of Liquids in Porous Mediums, Journal of Physics. 1, pp. 318-333, 1931.

[13] Saxton, K.E. and Rawls, W.J., Soil Water Characteristic Estimates by Texture and Organic Matter for Hydrologic Solutions. Journal of Soil Science Society of America. 70, pp. 1569-1578, 2006.

[14] Brooks, R.H., and Corey, A.T., Hydraulic Properties of Porous Media. Hydrology Paper No. 3, Colorado State University, Fort Collins, Colorado, $27 \mathrm{p}, 1964$.

[15] Mualem, Y., A New Model for Predicting the Hydraulic Conductivity of Unsaturated Porous Media. Journal of Water Resource Research. 12, pp. 513-522, 1976.

[16] Hill, R.W., Irrigation Scheduling (Chapter 12), Modelling Plant and Soil Systems. Edited by Hanks, J. and Ritchie, J.T., ASA-CSSA-SSSA, Madison, Wisconsin, USA, Journal of Agronomy Monograph. 31, pp. 491509, 1991.

[17] Cuenca, R.H., Irrigation System Design, An Engineering Approach. USNRCS 71, pp. 236-242, 1989.

[18] Phocaides, A., Technical Handbook on Pressurized Irrigation Techniques. FAO Consultant, Rome, 195 p, 2000.

[19] Rhoades, J.D., Drainage for salinity control. Drainage for Agriculture, Madison, Journal of Agronomy Monograph. 17, pp. 433-461, 1974.

[20] Schleiff, U., Research Aspect for Crop Salt Tolerance under Irrigation with Special Reference to Root Environment. Recent Advances in Agricultural Chemistry. Edited by Haneklaus, S., Rietz, M.R., Rogasik, J., Schroetter, S., Landbauforchung Völkenrode. Special Issue 286, pp. 83-94, 2005.

[21] Male, D.H., and Granger R.J., Snow Surface Energy Exchange, Journal of Water Resources Research. 17, pp. 609-627, 1981.

[22] Cardon, G.E., and Letey, J., Soil-based Irrigation and Salinity Management Model I. Plant Water Uptake Calculations. Journal of Soil Science Society of America.56, pp. 1881-1887, 1992.

[23] Monteith, J.L., Evaporation and Environment. In: The State and Movement of Water in Living Organisms. Cambridge University Press, Journal of Symposia of Society for Experimental Biology. 19, pp. 205-234, 1965.

[24] Gieske, A., Dynamics of Groundwater Recharge- A Case Study in SemiArid Eastern Botswana. PhD Thesis, Vrije Universiteit, Netherlands, 289 p, 1992. 